\title{
Structural properties of metal closo-polyborates and their relevance to energy storage applications
}

Vitalie Stavila

Sandia National Laboratories, Livermore, CA 94551

E-mail:vnstavi@sandia.gov

Metal closo-polyborates have been explored as materials for hydrogen storage and as promising ionic conductors. However, their utility as hydrogen storage media is hindered by high thermal stability, kinetic limitations, side reactions, and complicated phase transitions. Recent literature suggests that metal closopolyborates such as $\mathrm{Li}_{2} \mathrm{~B}_{12} \mathrm{H}_{12}$ and $\mathrm{Li}_{2} \mathrm{~B}_{10} \mathrm{H}_{10}$ are formed as stable intermediates during the dehydrogenation of metal borohydrides. This hypothesis is especially intriguing in the context of high thermal stability reported for these compounds. Here, a series of alkali, alkaline-earth and transition metal $\left[\mathrm{B}_{12} \mathrm{H}_{12}\right]^{2-}$ and $\left[\mathrm{B}_{10} \mathrm{H}_{10}\right]^{2-}$ compounds were isolated and characterized by single-crystal and powder X-ray diffraction techniques. Attempts to rehydrogenate $\mathrm{M}_{2} \mathrm{~B}_{12} \mathrm{H}_{12}$ and $\mathrm{M}_{2} \mathrm{~B}_{10} \mathrm{H}_{10}$ (where $\mathrm{M}=$ alkali metal) materials in the presence of the metal hydrides were made, and several compounds were found to susceptible to dehydrogenation/rehydrogenation reactions. In addition, $\mathrm{M}_{2} \mathrm{~B}_{12} \mathrm{H}_{12}$ and $\mathrm{M}_{2} \mathrm{~B}_{10} \mathrm{H}_{10}$ compounds were found to display high ionic conductivity due to order-disorder phase transitions. The synthesisstructure-property relationships in metal closo-polyborates and their potential in various energy storage applications will be also discussed. 